\title{
Laparoscopic Sleeve Gastrectomy Feasible for Bariatric Revision Surgery
}

\author{
Cornelis Adrianus Sebastianus Berende • \\ Jean-Paul de Zoete • Johannes Franciscus Smulders • \\ Simon Willem Nienhuijs
}

Published online: 25 August 2011

(C) The Author(s) 2011. This article is published with open access at Springerlink.com

\begin{abstract}
Bariatric revision surgery is associated with several complications that can be attributed to decreased quality of tissue and complexity of the surgery. A laparoscopic sleeve gastrectomy is a simple technique with potential advantages. Therefore, the results of this procedure were evaluated as a revisional option. Fifty-one patients underwent laparoscopic sleeve gastrectomy (LSG). Indications for the LSG were insufficient weight loss (34 patients, group 1) or vomiting (17 patients, group 2) following a laparoscopic adjustable gastric banding (LAGB) or vertical banded gastroplasty (VBG). Patient and procedure characteristics as well as outcome were collected prospectively. From October 2006 to June 2010, 51 patients with a failed prior bariatic procedure (VBG or LAGB) were converted to (L)SG. The conversion rate was zero. The median procedure time was 99 min (range 54221) and hospital stay was 3 days (range 2-38). There was no mortality after 30 days. Complications included bleeding (six) and leakage of the staple line (seven). Mean follow-up was 13.8 (2-46) months. LSG as revision surgery for insufficient weight loss resulted in extra weight loss of $52.7 \%$, and the overall extra weight loss was $49.3 \%$. When LSG was performed because of vomiting, $82 \%$ was able to eat solid food at follow-up. Of the 65 pre-existent comorbidities, 21 were resolved and 18 improved. LSG as a revision procedure is feasible. An additional weight loss and further resolution of co-morbidity seem achievable, however, at the cost of a high number of complications.
\end{abstract}

C. A. S. Berende $(\triangle) \cdot$ J.-P. de Zoete $\cdot$ J. F. Smulders $•$

S. W. Nienhuijs

Catharina Hospital,

Eindhoven, the Netherlands

e-mail: niels.berende@cze.nl
Therefore, revision bariatric surgery should be limited to expert tertiary bariatric centers.

Keywords Gastric banding · Revision · Sleeve gastrectomy Failure

\section{Introduction}

In the late 1990s, gastric banding (LAGB) and vertical banded gastroplasty (VBG) were popular bariatric procedures. Initially good results with $54-58 \%$ weight loss [1] were reported. However, extended follow-up showed high failure rates $(20-56 \%)[2,3]$. The most common failures are related to pouch dilation or slippage. Other causes could be band erosion, tubing leakage, or port site trouble (inversion, hernia, or pain) [4].

There are several options after a failure of a restrictive procedure such as re-do banding in case of band-related failure, conversion to Roux-en-Y gastric bypass (RYGBP), duodenal switch (DS), or biliopancreatic diversion (BPD) [5]. However, bariatric revision surgery is associated with a higher complication rate than primary procedures [6] independent of the used technique.

In 1998, the first laparoscopic sleeve gastrectomy (LSG) was performed as a component of Hess' biliopancreatic diversion with duodenal switch (BPD-DS) [7]. The effect of sleeve gastrectomy is believed to be based on restriction and reduction of ghrelin by removal of the orexigenic cells and accelerated gastric emptying $[8,9]$. It was first used as a two-step procedure for the superobese but showed good weight loss and resolution of co-morbidities with low complication rates [10-12]. Therefore, LSG becomes more popular as a stand-alone procedure and long-term results are promising [13]. 
The experience in our center with sleeve gastrectomy as a primary procedure is now over 500 procedures. Because of the advantages of LSG, this procedure was chosen as a revision option after prior LAGB or VBG. These results were evaluated in the present study.

\section{Methods}

Patients

From October 2006 to June 2010, 51 patients (11 men and 40 women) with a failed prior bariatic procedure (VBG or LAGB) were converted to LSG. Group 1 had insufficient weight loss (34 patients) and group 2 had complaints of passage or vomiting (17 patients).

In group 1, the weight loss after revision surgery was expressed as percentage of excess body mass index (EBMI):

$\%$ EBMI loss $=\frac{\text { preop BMI }- \text { current BMI } \times 100}{\text { preop BMI }-25}$

\section{Operative Technique}

All patients received low molecular weight heparin preoperative for venous thromboembolism prophylaxis. Additionally, pneumatic stockings (Sequential Compression Stockings ${ }^{\circledR}$ (Covidien, Elancourt Fr)) were used during the intervention. A second-generation cephalosporin (cephazoline $2.0 \mathrm{~g}$ iv) was applied perioperative. The patient was positioned in French position (supine with legs apart and arms abducted) with the surgeon standing between the legs. The abdomen was insufflated with a Veress needle at Palmer's point to a pressure of $18 \mathrm{mmHg}$. A four or five trocar technique was used. The first $12-\mathrm{mm}$ visiport trocar was placed $20 \mathrm{~cm}$ distal to the xiphoid process for the $30^{\circ}$ optical system. One $5-\mathrm{mm}$ trocar was placed just below the xiphoid process on the left side and the other two trocars were placed in the mid-clavicular line right and left side $5 \mathrm{~cm}$ distal to the costal margin (right $15-\mathrm{mm}$ and left 12-mm trocar). The liver was retracted with a $5-\mathrm{mm}$ liver retractor. If the procedure was postLAGB, the band was freed of adhesions and the total circumference was exposed by sectioning the gastrogastric tunnel covering the band. Then the band is removed. On the judgement of the surgeon, a one-stage or two-stage strategy is followed (proceed directly to LSG or planned LSG after 3 months). Regardless of the stage, no buttressing was used.

When LSG is done, the greater curvature of the stomach was freed from the greater omentum, starting opposite the crow's foot, with the LigaSure ${ }^{\circledR}$ (Covidien, Elancourt Fr), dissecting proximally until the left crus and angle of His were reached and distally towards the pylorus sparing $6 \mathrm{~cm}$ of the proximal antrum. The stomach was transected with an Endogia $^{\circledR}$, loaded with one or two green and four blue cartridges (average) (Covidien, Elancourt Fr), under guidance of a 34-F orogastric tube pressed along the lesser curvature. If the procedure was post-VBG, the transaction was up to the former staplers. Band was removed if possible, split if impossible $\left(\right.$ Marlex $\left.^{\circledR}\right)$. Due to dilatation of the pouch, a new staple line was again within the old staple line in all cases. The excluded part of the stomach was extracted from the abdomen through the somewhat enlarged $15-\mathrm{mm}$ trocar site. This 15-mm fascia lesion is closed with an EndoClose ${ }^{\circledR}$ (Covidien, Elancourt $\mathrm{Fr}$ ) with an absorbable suture. The gastric tube was removed, $\mathrm{CO}_{2}$ released, and trocars removed. Skin was closed intracutaneously.

\section{Postoperative Management}

Usually, patients were discharged at the third postoperative day with liquid diet advised for 3 weeks. All patients received Fragmin ${ }^{\circledR}$ (Pfizer, New York, USA) 5000eh once a day and TED socks (Covidien, Elancourt Fr) for 4 weeks. Meanwhile, 3 months of a PPI once a day was prescribed.

\section{Data Collection}

Prospectively collected data were patient and procedure characteristics as well as outcome. In case of incompleteness of data, a questionnaire was sent to the patients and the patients were contacted by telephone. All data are presented as median (range) unless otherwise stated. No statistical evaluation was performed due to the small study population.

\section{Results}

At the time of revision, median age was 39.2 years (range 1965 years) and median BMI was $41.0 \mathrm{~kg} / \mathrm{m}^{2}\left(25-61 \mathrm{~kg} / \mathrm{m}^{2}\right)$. The median BMI before the primary surgery was $45.3 \mathrm{~kg} / \mathrm{m}^{2}$ (range $35-77 \mathrm{~kg} / \mathrm{m}^{2}$ ) and post-primary surgery was $30.6 \mathrm{~kg}$ / $\mathrm{m}^{2}$ (range $23-61 \mathrm{~kg} / \mathrm{m}^{2}$ ).

The median procedure time was 99 min (range 54-221) and hospital stay was 3 days (range 2-38). Mean follow-up was $13.8(2-46)$ months.

There was no mortality in this group. Of the 51 patients, 47 procedures were performed laparoscopically of which 4 previously had open surgery, and 4 procedures were performed after prior open surgery. There were no conversions and the open procedures were prior open procedures and were planned open due to expected adhesions (see flow chart). 


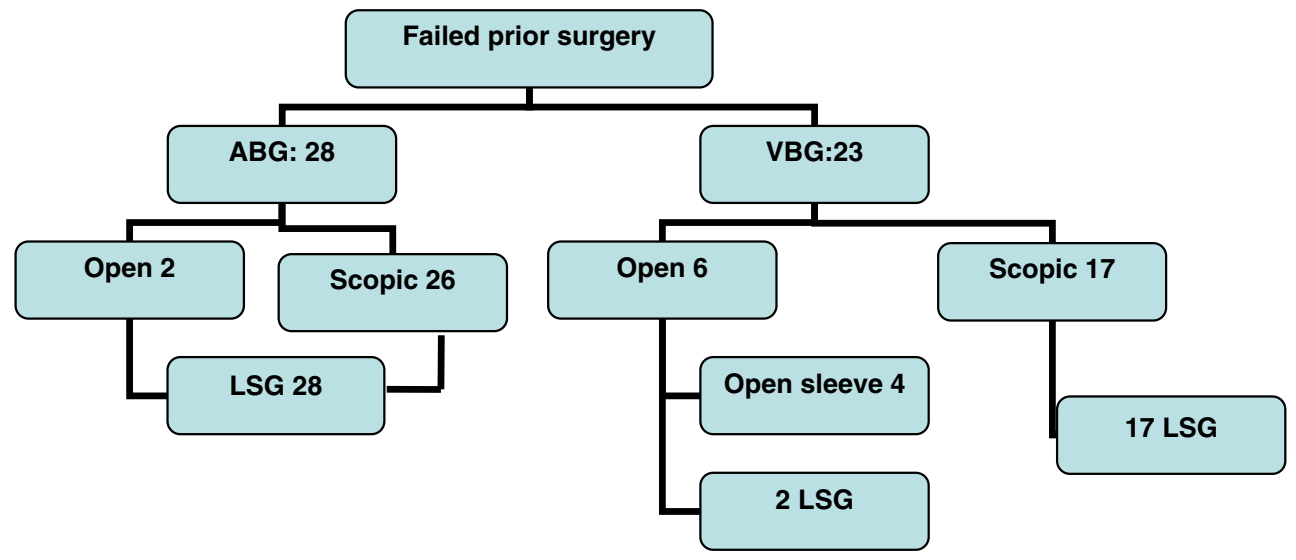

The main complications were one intraoperative splenic lesion (2.0\%), of which a hand-assisted splenectomy was performed, five bleedings (9.8\%) (one re-intervention) and seven leakages of the staple line (14\%) treated with two re-interventions (3.9\%), five (repeated) CT-guided drainages $(9.8 \%)$, and three endoscopically positioned stents $(6 \%)$. Extended length of stay associated with leakage was 13 days (median 16 and range 4-38).

In the post-LAGB group (28 patients), in 15 cases (54\%) a "one-stage" strategy was followed and 13 times (46\%) a "two-stage" strategy. The complication rate in our "twostage" strategy was $7.7 \%$ (one bleeding), which was treated conservatively. No leakage or abscesses occurred. In the "one-stage" strategy, however, three bleedings $(20 \%)$ and five leakages (33\%) occurred which led to five abscesses which were treated by CT-guided drainages and IV antibiotics and in two cases by an endoscopically placed covered stent (see Table 1).

Of the 51 patients, 65 obesity-related co-morbidities, including hypertension in 16 (31\%), type II diabetes mellitus in $8(16 \%)$, degenerative joint disease in 27 (49\%), hyperlipidemia in $9(18 \%)$, and sleep apnea in 5 (10\%) existed.

Table 1 Complication rates

\begin{tabular}{lcc}
\hline Former procedure & One stage $(n)$ & Two stage $(n)$ \\
\hline AGB & 15 & 13 \\
Leakage & $5(33 \%)$ & $0(0 \%)$ \\
Bleeding & $3(20 \%)$ & $1(7.7 \%)$ \\
VBG & 23 & \\
Leakage & $2(8.6 \%)$ & - \\
Bleeding & $2(8.6 \%)$ & - \\
Complication rate & $32 \%$ & $7.7 \%$ \\
\hline
\end{tabular}

LSG as a revision surgery for insufficient weight loss resulted in extra weight loss of $52.7 \%$, and the overall extra weight loss was $49.3 \%$ (see Table 2). When LSG was performed because of vomiting, $82 \%$ of the patients were able to eat solid food at follow-up. Of the 65 pre-existent comorbidities, 21 were resolved and 18 improved (see Table 3).

\section{Discussion}

In the 1990s, gastric banding (LAGB) or VBG became popular restrictive bariatric procedures. Initially good results were achieved with a $54-58 \%$ weight loss [3]. However, longer follow-up showed high rates of failure $(20-56 \%)[1,2]$ demanding revisional surgery. Conversion to RYGBP, DS, or BPD [5] and sleeve gastrectomy (SG) are available techniques following AGB or VBG. Most of these revisions can be done laparoscopically.

LSG itself is a viable option in staged surgery in the (high-risk) superobese and becomes more popular as a definitive single-stage option for morbid obesity $[6,10]$. LSG does not alter bowel continuity, and there are no mineral and vitamin deficiencies, except potential vitamin

Table 2 Weight loss and BMI

\begin{tabular}{lcc}
\hline & Total group & $\begin{array}{l}\text { Group 1 } \\
\text { (insufficient weight loss) }\end{array}$ \\
\hline Pre-weight (mean, kg) & 120.3 & 127.6 \\
Post-weight (mean, kg) & 99.8 & 103.7 \\
Weight loss (kg) & 20.5 & 23.9 \\
Pre-BMI (mean) & 39.8 & 43.2 \\
Post-BMI (mean) & 32,5 & 33.6 \\
BMI loss (kg/m ${ }^{2}$ ) & -7.3 & -9.6 \\
\% BMI loss & 49.3 & 52.7 \\
\hline
\end{tabular}


Table 3 Overall resolution of co-morbidities after reoperations (percent)

\begin{tabular}{llrrr}
\hline & Number & Gone & Improved & \multicolumn{1}{l}{ Stable } \\
\hline Hypertension & 16 & $2(12 \%)$ & $6(38 \%)$ & $8(50 \%)$ \\
Hypercholesterolemia & 9 & $2(22 \%)$ & 0 & $7(78 \%)$ \\
Sleep apnea & 5 & $2(40 \%)$ & $1(20 \%)$ & $2(40 \%)$ \\
Diabetes type II & 8 & $3(38 \%)$ & $4(50 \%)$ & $1(12 \%)$ \\
Deg. joint disease & 27 & $12(44 \%)$ & $7(26 \%)$ & $8(30 \%)$ \\
Total & 65 & $21(32 \%)$ & $18(28 \%)$ & $26(40 \%)$ \\
\hline
\end{tabular}

$\mathrm{B}_{12}$ deficiency $[13,14]$. The overall complication rate of primary LSG is very acceptable $(5-10 \%)[15,16]$, and the mortality rate associated with this procedure is very low.

In our surgical center, we performed both LRYGBP and LSG as bariatric procedures. In these particular cases where revision is needed, also LRYGBP and LSG are both surgical options. The indications for LSG as a revision option were experience with this procedure, patients personal preference, and relative contra-indications for other techniques such as lots of drug use. The overall complication rate for (L) SG as revision of AGB or VBG is higher compared to LSG as a primary procedure (13-34\%) [17-19]. The different complication rates in primary versus revision procedures are probably explained by trauma of the inferior tissue, stapling in inflammatory tissue due to the band, and dissection of former adhesions with possible damage of compromised tissue. Also, a compromised vascular supply of the superior aspect of the staple line, due to dissection of the left crus, may be a factor.

The published expected \%EBMI loss after revision LSG is $42-46 \%$ at 12 months of follow-up [17, 20]. These results are slightly worse than after RYGPB where up to $60 \%$ is achievable [21]. Also co-morbidities will further reduce or even resolve after revision LSG in the majority of the treated patients. This could be as much as $50 \%$ improvement $[17,21]$.

As mentioned in our series, we had a total complication rate of $25 \%(13 / 51)$ with no mortality, which is acceptable compared with literature (13-34\%). The leakage rate of our series was $14 \%$ (seven), i.e., two (8.7\%) following VBG and five following an AGB (17.9\%). However, if our "twostage" strategy ( $46 \%$ of our cases) was performed after AGB, no leakage or abscesses were reported. The only complication in this group was bleeding which was treated conservatively.

In our opinion, a waiting period of 3 months allows tissue to regenerate in order to reduce the risk of leakage. At this moment, there is still no evidence in literature about this.

In group 1 (insufficient weight loss), the \%EBMI loss was $52.7 \%$, and the overall $\%$ EBMI loss was $49.3 \%$, which is comparable to earlier published results for LSG as a revisional option [17]. There is still a discussion on the exact definition of percent excess BMI. Defining a BMI of $25 \mathrm{~kg} / \mathrm{m}^{2}$, the upper limit of normal in line with current anthropometric definitions of obesity as a target for weight loss remains arbitrary. Using a lower than maximum ideal body weight would decrease the percentage of weight loss. As most other studies use a BMI of 25 as a starting point, the same definition was used in the present study.

In our series, the co-morbidities improved in $28 \%$ and even resolved in $32 \%$ of the patients. This is as good as earlier published or even slightly better. We had one $(2 \%)$ uncontrollable bleeding of the spleen that was resolved using a hand-assisted splenectomy. This was after an open AGB with loss of adhesions. Our series is a relatively small retrospective study with an intermediate follow-up of 14 months. But it is still one of the largest published series using SG as a revision option for AGB and VBG.

In summary, we concluded that LSG is a feasible option as a revision procedure after VBG or AGB with a high, but acceptable, complication rate. In our opinion a "two-stage" procedure should be followed to reduce leakage risks after an initial AGB, and revision bariatric surgery should be limited to expert (high volume) tertiary centers.

Conflicts of Interest None.

Open Access This article is distributed under the terms of the Creative Commons Attribution Noncommercial License which permits any noncommercial use, distribution, and reproduction in any medium, provided the original author(s) and source are credited.

\section{References}

1. Suter M, Calmes JM, Paroz A, et al. A 10 year experience with laparoscopic gastric banding for morbid obesity: high long-term complication and failure rates. Obes Surg. 2006;16 (7):829-35.

2. Van Gemert WG, Van Wersch MM, Greve JMW, et al. Revisional surgery after vertical banded gastroplasty: restoration of vertical banded gastroplasty or conversion to gastric bypass. Obes Surg. 1998;8:21-8.

3. Favretti F, Segato G, Ashton D, et al. Laparoscopic adjustable gastric bandingin 1,791 consecutive obese patients: 12-year results. Obes Surg. 2007;17:168-75.

4. Gagner M, Gumbs AA. Gastric banding: conversion to sleeve, bypass, or DS. Surg Endosc. 2007;21:1931-5.

5. Acholonu E, McBean E, Rosenthal RJ, et al. Safety and short-term outcomes of laparoscopic sleeve gastrectomy as a revisional approach for failed laparoscopic adjustable gastric banding in the treatment of morbid obesity. Obes Surg. 2009; 19:1612-6.

6. Deitel M, Crosby RD, Gagner M. The first international consensus summit for sleeve gastrectomy (SG), New York City, Oct 25-27 2007. Obes Surg. 2008;18:487-96. 
7. Lalor PF, Tucker ON, Rosenthal RJ, et al. Complications after laparoscopic sleeve gastrectomy. Surg Obes Relat Dis. 2008;4:338.

8. Langer FB, Reza Hoda MA, Bohdjalian A, et al. Sleeve gastrectomy and gastric banding: effects on plasma ghrelin levels. Obes Surg. 2005;15:1024-9.

9. Karamanakos SN, Vagenas K, Kalfarentzos F, et al. Weight loss, appetite suppression, and changes in fasting and postprandial ghrelin and peptide-YY levels after Roux-en-Y gastric bypass and sleeve gastrectomy: a prospective, double blind study. Ann Surg. 2008;247:401-7.

10. Silecchia GF, Boru C, Pecchia A, et al. Effectiveness of laparoscopic sleeve gastrectomy (first stage of biliopancreatic diversion with duodenal switch) on co-morbidities in super-obese high-risk patients. Obes Surg. 2006;16:1138-44.

11. Nocca D, Krawczykowsky D, Bomans B, et al. A prospective multicenter study of 163 sleeve gastrectomies: results at 1 and 2 years. Obes Surg. 2008;18:560-5.

12. Gumbs AA, Gagner M, Dakin G, et al. Sleeve gastrectomy for morbid obesity. Obes Surg. 2007;17:962-9.

13. Brethauer SA, Hammel JP, Schauer PR. Systematic review of sleeve gastrectomy as staging and primary bariatric procedure. Surg Obes Relat Dis. 2009;5(4):469-75.

14. Iannelli A, Dainese R, Piche T, et al. Laparoscopic sleeve gastrectomy for morbid obesity. World J Gastroenterol. 2008;14:821-7.
15. Fuks D, Verhaeghe P, Regimbeau JM, et al. Results of laparoscopic sleeve gastrectomy: a prospective study in 135 patients with morbid obesity. Surgery. 2009;145(1):106-13.

16. Nienhuijs SW, de Zoete JP, Smulders JF, et al. Evaluation of laparoscopic sleeve gastrectomy on weight loss and co-morbidity. Int J Surg. 2010;8(4):302-4.

17. Ianneli A, Schneck A, Gugenheim J, et al. Laparoscopic sleeve gastrectomy as revisional procedure for failed gastric banding and vertical banded gastroplasty. Obes Surg. 2009;19:1216-20.

18. Foletto M, Prevedello L, Nitti D, et al. Sleeve gastrectomy as revisional procedure for failed gastric banding or gastroplasty. Surg Obes Relat Dis. 2010;6(2):146-51.

19. Spyropoulos C, Kehagias I, Kalfarentzos F, et al. Revisional bariatric surgery: 13-years experience from a tertiary institution. Arch Surg. 2010;145(2):173-7.

20. Uglioni B, Wölnerhanssen B, Peters T, et al. Midterm results of primary vs. Secundary laparoscopic sleeve gastrectomy (LSG) as an isolated operation. Obes Surg. 2009;19:401-6.

21. Mechanick J, Kushner R, Sugerman H, et al. for the American Association of Clinical Endocrinologists; Obesity Society; American Society for Metabolic and Bariatric Surgery medical guidelines for clinical practice for the perioperative nutritional, metabolic, and nonsurgical support of the bariatric surgery patient. Obesity (Silver Spring). 2009;17 suppl 1:S1-S70. 